\title{
Fiber optic-based in-cylinder pressure sensor for advanced engine control and monitoring
}

\begin{abstract}
This paper describes the design and performance of a miniature cylinder pressure sensor packaged either as a stand-alone device or integrated with a cylinder head gasket, glow plug, fuel injector, or spark plug. Benefitting from a fiber-optic based design the sensing element can operate at ultra-high temperatures and is not affected by EMI. This low cost device utilizes the principle of light intensity changes transmitted by two optical fibers upon reflection from a metal diaphragm deflecting under the effect of pressure. When the diaphragm thickness and shape are optimized, the sensor can operate up to 5 billion pressure cycles. The device is compensated for all temperature effects encountered in combustion engines, resulting from the thermal shock, engine load changes, and under-hood temperature fluctuations. Due to the diaphragm small thermal mass the sensor is subject to the thermal shock error if no heat shield is employed. While a suitable shield can almost eliminate the thermal shock error, it can get clogged in engines fuelled by diesel or landfill gas. For such engines a dual diaphragm construction offers a robust solution against soot and other combustion deposits as well as minimum thermal shock error. In comparison to a water cooled piezoelectric quartz transducer the present sensor offers the accuracy of $\pm 1.5 \%$ of reading at pressures above 5 bars, \pm 0.1 bar error at pressure below 5 bars during compression, and the thermal shock error ranging from 0.1 bar to 0.3 bar dependent if a single or dual diaphragm is used. Such accuracy is possible with both stand-alone sensors as well as those $1.7 \mathrm{~mm}$ in diameter used in the "pressure sensing" cylinder head gaskets, glow plugs, fuel injectors, or spark plugs. This accuracy is maintained under all combustion conditions, sensor tip continuous temperatures up to $380^{\circ} \mathrm{C}$, signal conditioner temperature range of $-40{ }^{\circ} \mathrm{C}$ to $140^{\circ} \mathrm{C}$, pressures up to $350 \mathrm{bar}$, and over frequency range of $0.1 \mathrm{~Hz}$ to $30 \mathrm{kHz}$. Such remarkable accuracy allows advanced engine controls based on highly accurate values of the Indicated Mean Effective Pressure, Mass Fraction Burned, Maximum Pressure Gradient, and Peak Pressure. Benefitting from sensor's high accuracy at both low and high pressures the device enables closed-loop control of fuel injection as well as in-cylinder prediction of mass air flow and engine $\mathrm{NO}_{x}$ emission levels.
\end{abstract}

Key words: cylinder, pressure, sensor, engine, control

\section{Introduction}

For the last 30 years numerous manufacturers of light duty internal combustion engines have attempted to develop control strategies based on a Cylinder Pressure Sensor (CPS) [1], which culminated in 2008 in the introduction of the first cylinder pressure-controlled clean diesel 4-cylinder and 6-cylinder engines [2]. Through the closed loop control of Mass Fraction Burned and Indicated Mean Effective Pressure the engine features substantially reduced in-cylinder emissions of $\mathrm{NO}_{x}$ and soot, lower engine noise levels, and improved fuel economy and drivability [3, 4]. Other benefits of cylinder pressure-based closed loop combustion controls include: stability over lifetime (tolerances, emissions), elimination and/or simplification of other engine sensors, reduction application effort (simplified engine maps), enabling highest power-density, on-board diagnostics (OBD), compensation for fuel quality, torque feedback and control, improved cold-starting and engine warm-up.

Other CPS-based engine control applications that recently gained significant interest are based on novel combustion concepts such as homogenous charge compression ignition (HCCI) [5], premixed charge compression ignition (PCCI) [6], and reactivity controlled compression ignition (RCCI) [7], which offer promise of substantial efficiency improvements combined with significant emissions reduction in gasoline, diesel, and alternative fuel engines.

\section{Current status of CPS targeting series production engines}

During the last 30 years of the development of different CPS technologies targeting series production engines various sensor packages have been considered to measure combustion pressure of internal combustion engines through a port in the cylinder head, spark plug, glow plug, fuel injector, or cylinder head gasket. All these solutions have their advantages and limitations. The cylinder head, using a dedicated port, is an obvious solution and works for all internal combustion engines with space permitting, but with compromise of structural rigidity. The spark plug offers an opportunity for ignition type engines as an integrated product $[8,9]$. Design challenges for this solution are the high temperature exposure of the CPS due to the location and the close proximity to high electromagnetic noise, both favouring a fiber optic based solution. A piezoelectric quartz pressure sensor [10] integrated with an engine cylinder head gasket $(\mathrm{CHG})$ has some inherent advantages of such integration over stand alone or spark plug-mounted sensors including suitability for use in all types and sizes of engines and different fuels, considerably lower cost especially in engines with a large number of cylinders, and compactness of the solution with a minimum number of connectors and harnesses needed. However, due to the sensor diameter of $3.5 \mathrm{~mm}$ the gasket thickness had to be increased from a typical $\sim 1 \mathrm{~mm}$ to 5 $\mathrm{mm}$ making the design not suitable for a majority of smaller engines. It is only a $1.8 \mathrm{~mm}$ diameter fiber-optic pressure 
sensor that has so far enabled a $3.0 \mathrm{~mm}$ thick cylinder head gasket [11].

The detection principle of the pressure sensor glow plug (PSG) [12] currently in use in series production light duty diesel engines relies on the heating rod axial displacement associated with changing cylinder pressure transmitting the motion to deflect the device diaphragm with a piezoresistive silicon strain gauge located on the of glow plug top. While the PSG offers good performance at high pressures and no thermal shock error, its springmass principle is inherently prone to artefacts associated with engine vibration as well as valve and fuel injector actuation. The notch filter used by the sensor electronics dampens the heater axial resonance limiting at the same time knock detection capability required for applications in gasoline or gas engines.

A number of so called stand-alone CPS intended for mounting into a dedicated port drilled in the engine head has been under development for the last few years focusing on applications in emerging gasoline HCCI and similar engines. One sensor type is based on a piezoceramic load cell [13] responding to the pressure-related changes of the device stress loading. However, this sensor suffers from susceptibility to engine valve actuation and vibration artifacts, sensitivity to sealing torque, and temperature and drift errors. Another type of the stand alone CPS operates on the same principle as the PSG suffering from the same limitations associated with the device spring-mass principle. As a result, the sensor has poor low pressure detection accuracy and distorted frequency response prohibiting high fidelity detection of engine knock and engine control strategies based on low cylinder pressure signal.

In contrast to the CPS designs based on either piezoresistive or piezoceramic sensors, which both measure pressure indirectly, the fiber optic-based sensor described here relies on the direct effect of combustion pressure, which defects sensor diaphragm located in the device tip [14]. The design enables high detection accuracy over a wide frequency range and at low pressure during compression where alternative CPS technologies suffer from engine vibration artifacts. However, the direct exposure of sensor diaphragm to combustion gasses and associated rapid temperature changes are the sources of so called thermal shock error that needs to be minimized to attain high detection accuracy at low pressure during expansion cycle.

\section{Description of fiber optic-based pressure sensor}

The schematic diagram of the fiber-optic cylinder pressure sensor [14] Optrand has developed is shown in below (Fig. 1).

The sensor head, which can vary in diameter from 1.8 $\mathrm{mm}$ to $10 \mathrm{~mm}$ depending on the diaphragm diameter, consists of stainless steel housing with a welded hat-shaped diaphragm made of Inconel 718 alloy and a metal ferrule with two optical fibers sealed inside. By an optimum selec-

Fig. 1. Schematic diagram of fiber optic-based pressure sensor

tion of diaphragm thickness and geometry its fatigue life can be as high as 5 billion cycles and possibly more. The most recent improvement of the fiber to ferrule seal relies on a hermetic glass bond rated for the maximum temperature of either $420{ }^{\circ} \mathrm{C}$ or $510{ }^{\circ} \mathrm{C}$ enabling the maximum sensor tip temperature of $380{ }^{\circ} \mathrm{C}$ or $480{ }^{\circ} \mathrm{C}$, respectively. The other fiber ends are connected to the sensor signal conditioner. The diaphragm's inside surface is illuminated by the "delivering" fiber connected to a light source while the "receiving" fiber transmits light reflected from the diaphragm to a light detector. During sensor assembly the ferrule is advanced toward the diaphragm until the target gap is reached, at which time the ferrule is welded to the housing. Figure 2 shows examples of sensor head packages based on the $1.7 \mathrm{~mm}$ diameter diaphragms with different thicknesses - dependent of engine peak pressures, targeting integration with such engine components as a glow plug, cylinder head gasket, spark plug, or fuel injector.

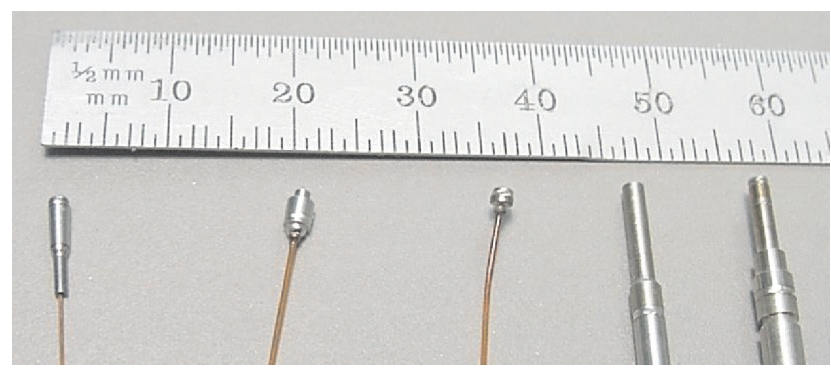

Fig. 2. Examples of sensor heads based on $1.7 \mathrm{~mm}$ diameter diaphragm

The key components of the sensor signal conditioner are an LED light source, a photodiode photo detector, and SMT electronic parts. Two large core fibers are permanently bonded to the LED (850 nm wavelength, 100 micron emitting area, point-source type) and photodiode (Silicon) chips. The Auto-Referencing circuitry [14] regulates the LED light intensity in a closed-loop control scheme so that the sensor offset is kept constant as the sensor head and signal conditioner temperatures change. In combination with the Temperature Compensation technique [14], closed loop LED control also corrects for the temperature dependence of sensor sensitivity associated with the diaphragm's deflection temperature 
dependence. The temperature compensation technique relies on an optimum selection of the sensor housing and ferrule thermal expansion coefficients and their lengths resulting in an increased diaphragm-to-ferrule gap with increasing sensor head temperature. The resulting increase in the reflected signal at minimum pressure is compensated by reducing the LED output by the auto-referencing circuitry, effectively reducing the sensor gain. This reduction is optimized to offset the effect of increased diaphragm deflection at increased temperature. Another advantage of the auto-referencing circuitry is its ability to maintain drift-free sensor offset under engine load changes and over the device's lifetime. Finally, the thermal error is kept at a minimum level owing to a heat shield installed in front of the sensor diaphragm. Various heat shield designs are used dependent on the engine type and level of soot deposits.

Over the last 15 years of sensor development the signal conditioner construction and size have been undergoing evolution from the original FiberPSI design shown in Fig. 3 based on a $100 \mathrm{~mm}$-wide and $200 \mathrm{~mm}$-long circuit board to an intermediate AutoPSI-A/I sensor shown in Fig. 4 based on a $25 \mathrm{~mm}$-wide and $75 \mathrm{~mm}$-long board to the latest AutoPSIOEI sensor shown in Fig. 5 based on a $12.7 \mathrm{~mm}$-wide and 20 mm-long board.

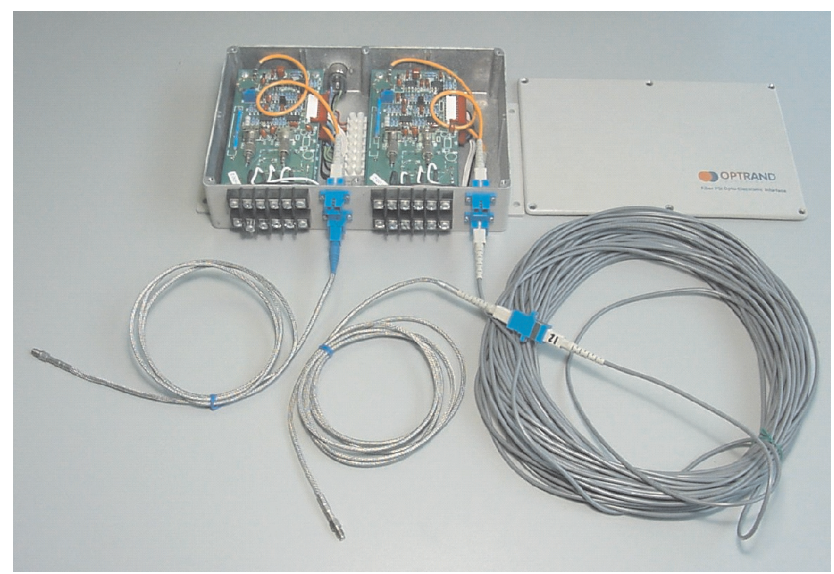

Fig. 3. Original FiberPSI pressure sensor with $100 \mathrm{~mm}$ x $200 \mathrm{~mm}$ circuit board
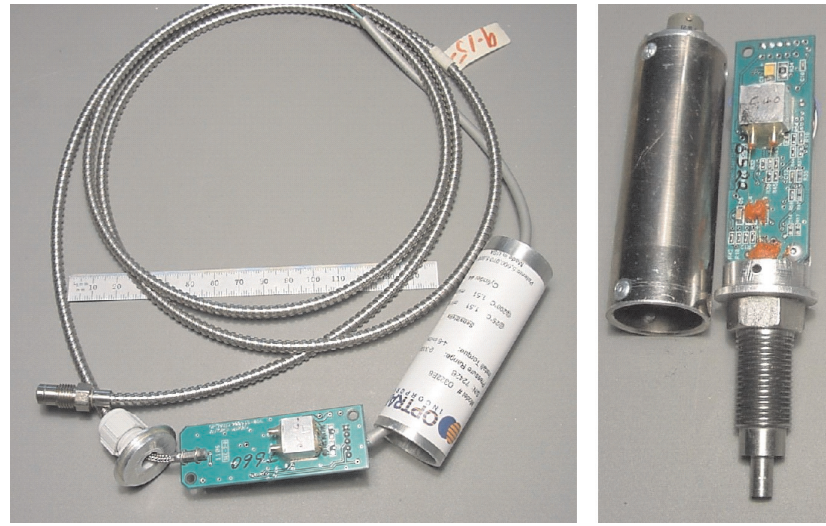

Fig. 4. AutoPSI-A and AutoPSI-I sensors based on a $25 \mathrm{~mm}$ x $75 \mathrm{~mm}$ circuit board

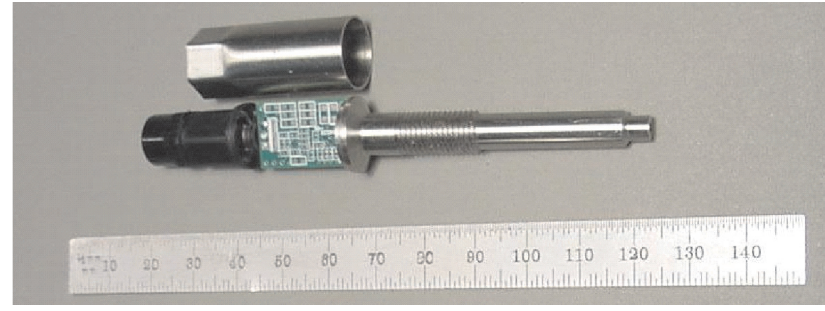

Fig. 5. Latest AutoPSI-OE sensor with 12.7 mm-wide x 20 mm-long circuit board

\section{Sensor packages targeting original equipment engines}

Benefitting from the miniature diaphragm, as small as $1.7 \mathrm{~mm}$ in diameter, several fiber optic-based CPS packages have been developed ranging from the "stand-alone" sensors of various shapes intended for mounting in dedicated bores of the engine head to a number of dual-function "pressure-sensing" engine components such as spark plugs, glow plugs, fuel injectors [15] or cylinder head gaskets [11] with CPS either permanently mounted or removable. Out of these packages three types are currently targeted for mass production, (1) stand alone CPS shown in Figs. 6 and 7, (2) glow-plugs with integrated sensors shown in Fig.8, and (3)
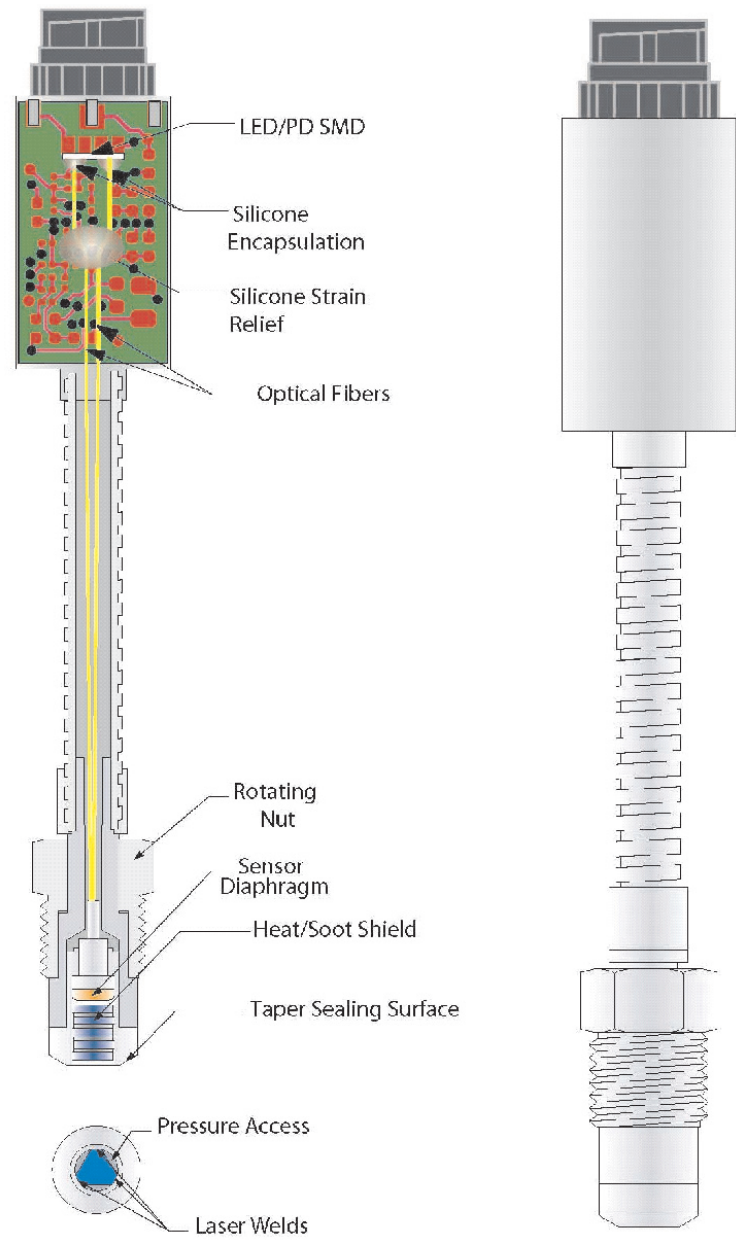

Fig. 6. Stand-alone AutoPSI-AI sensor for installation into dedicated bore in engine head 
sensors installed into a Cylinder Head Gasket (CHG) shown in Fig. 9. Two stand-alone versions are offered, the AutoPSI-AI sensor shown in Fig. 6 having the signal conditioner connected to the sensor head by a $1.5 \mathrm{~m}$-long ruggedized fiber optic cable and the AutoPSI-OEI sensor shown in Fig. 7 with the signal conditioner integrated with the sensor body. In either case the present circuitry is based on miniature SMT LED, photodiode, and electronic components enabling parts fitting on a board $12.7 \mathrm{~mm}$ wide and $20 \mathrm{~mm}$ long. A future version of the conditioner will have most of the electronic parts replaced a custom ASIC reducing the circuit board length to $10 \mathrm{~mm}$. While a number of different connectors can be employed, a circular version similar to what is presently used in the commercial pressure sensor glow plug (PSG) is preferred due to installation advantages.

For applications in engines with small amount of combustion deposits such as gasoline, CNG, LPG, or similar the sensors come with heat-deposit shields, shown in Fig. 6 and 7 , which primary function is to minimize the thermal shock error by reducing the heat flux the sensor diaphragm is exposed to. The secondary function of the shield is to trap any combustion deposits/soot so any amount accumulated on the diaphragm over time cause minimum and tolerable accuracy errors. For engines with large levels of combustion/soot deposits such as fuelled by diesel or landfill gas the sensors use a dual diaphragm construction shown in Fig. 7, where an external diaphragm deflects the internal diaphragm via a short transfer pin. When such a dual-diaphragm sensor is installed in an engine with the external diaphragm flush with the fire deck any soot ac-
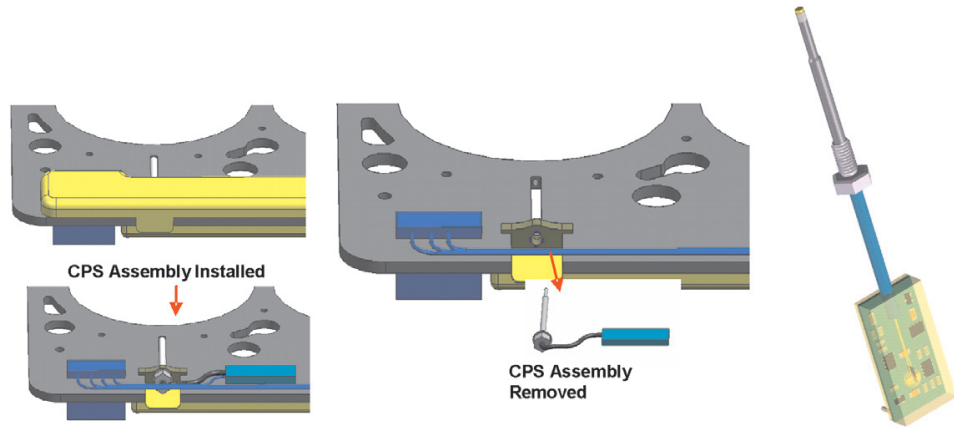

Fig. 9. Cylinder head gasket with installed miniature CPS
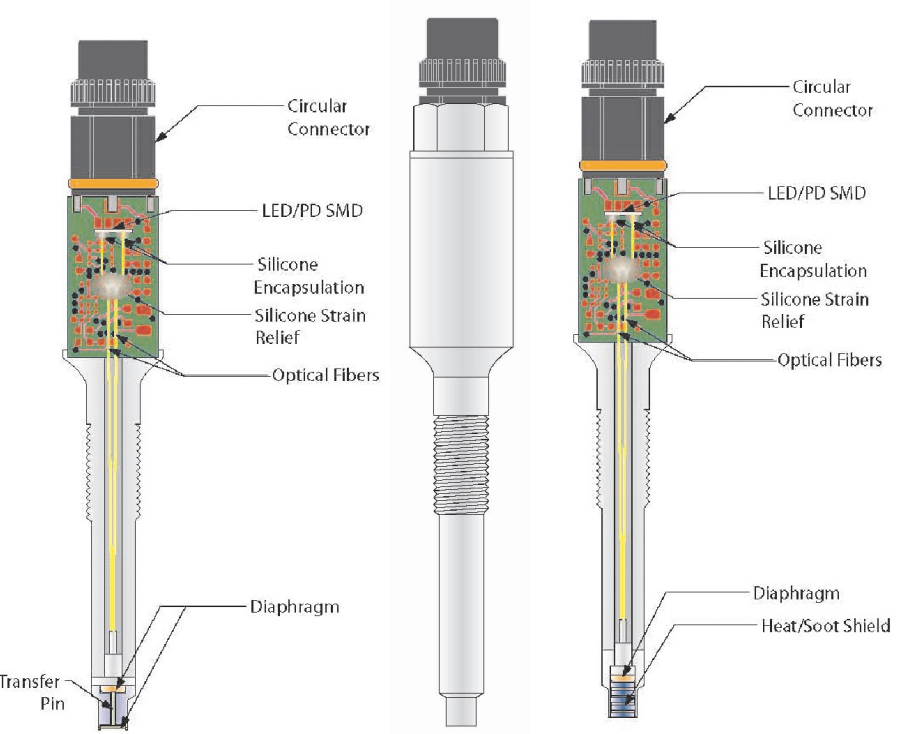

Fig. 7. AutoPSI-OE sensor with single and dual diaphragm
$600{ }^{\circ} \mathrm{C}$ resulting in burning off any soot deposits accumulated in the wire mesh filter. By backing of the diaphragm by $8 \mathrm{~mm} \div 10 \mathrm{~mm}$ from the orifice location the maximum temperature of the sensor tip is less than $\sim 350^{\circ} \mathrm{C}$ - sufficiently low for sensor stable operation during the lifetime up to $30 \mathrm{k}$ hours.

For applications in engines with minimum levels of combustion deposits such as gasoline, $\mathrm{CNG}$, or LPG, a CPS solution that offers cost and performance advantages is based on a custom Cylinder Head Gasket with installed in it $1.8 \mathrm{~mm}$ diameter sensors [11] - as shown in Fig. 9. For robustness and lowest cost the miniature signal conditioners of the sensors are attached to the gasket, protected by a hermetic cover and connected to the ECU by a single multi pin electrical connector.

\section{Sensor performance}

The performance of a stand-alone sensor with the $1.7 \mathrm{~mm}$ diameter diaphragm and a M3 x 0.5 thread 
Pressure vs Time vs $\triangle$ Pressure No Average

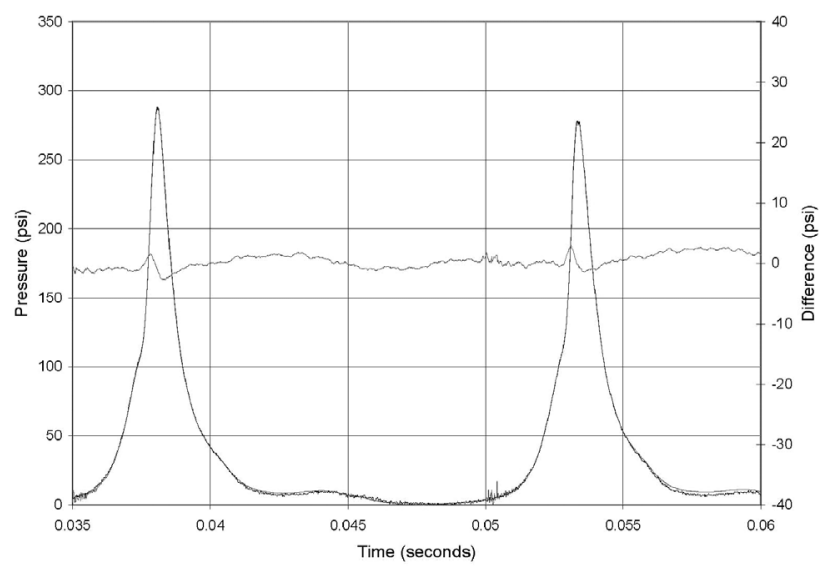

- Reference — Optrand — Difference (psi)

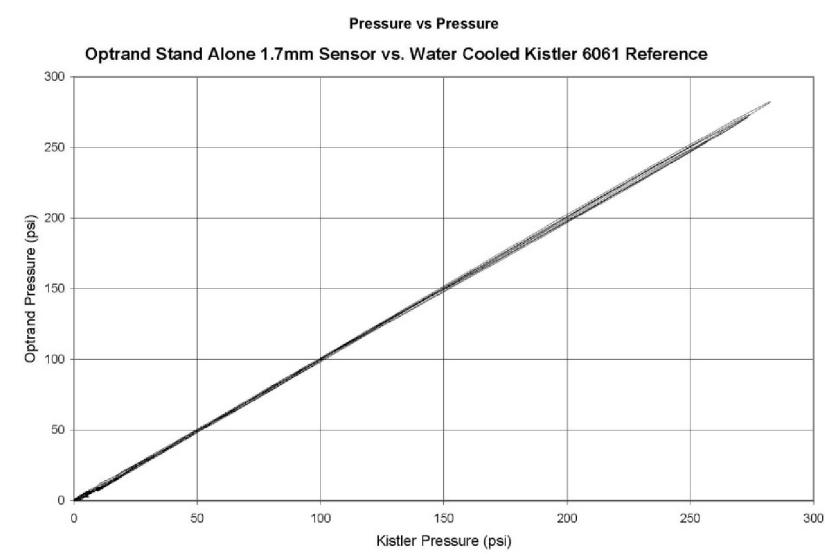

Fig. 10. Performance of M3 x 0.5 thread sensor in gasoline engine

is shown in Fig.10 obtained in a gasoline gen-set engine against a water-cooled Kistler 6061 reference transducer. Both sensors were installed into dedicated bores drilled into the single cylinder engine head. A heat/soot shield made of Inconel 600 wire mesh was inserted in front of the $1.7 \mathrm{~mm}$ diameter diaphragm. The data were collected using a 16 bit $\mathrm{ADC}$ at 50k samples per second against time while running the engine at full load and $3600 \mathrm{rpm}$. The overall sensor performance is within $\pm 1.5 \%$ of the reference transducer, as seen in the graphs below, demonstrating in addition good

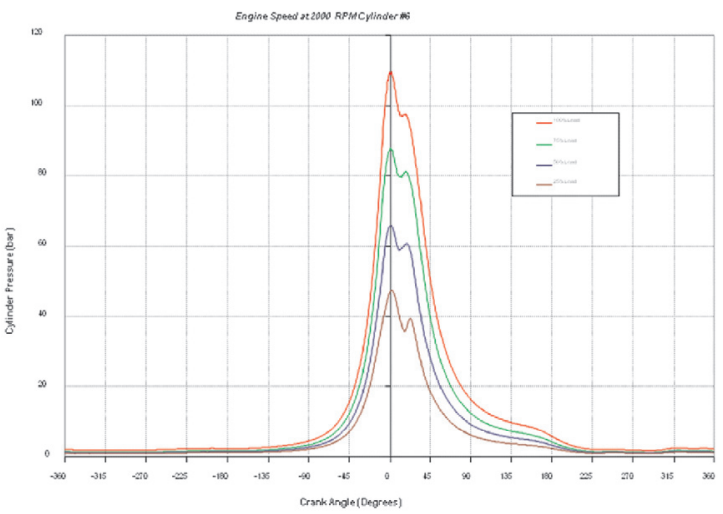

Pressure vs Time vs $\triangle$ Pressure No Average

Ricardo PSCGP prototype vs. water cooled Kistler 6061B Reference

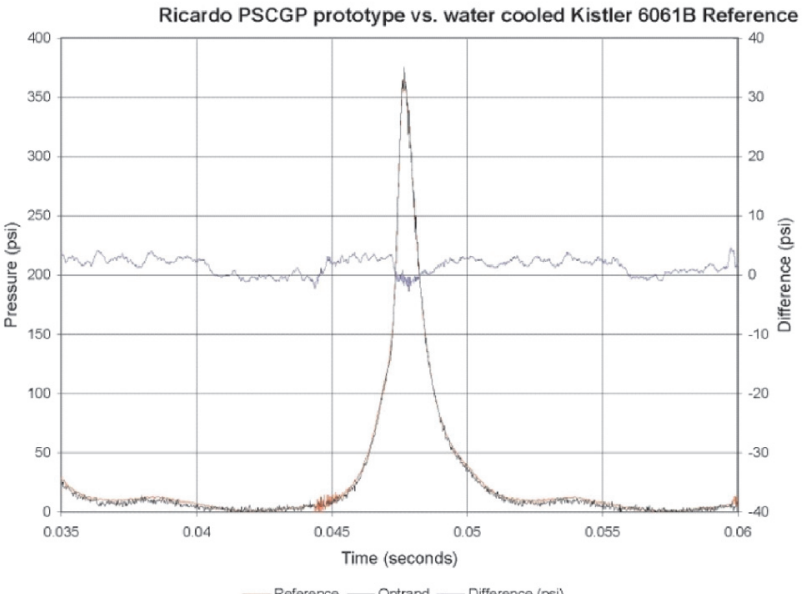

- Reference — Optrand — Difference (psi)

Pressure vs Pressure

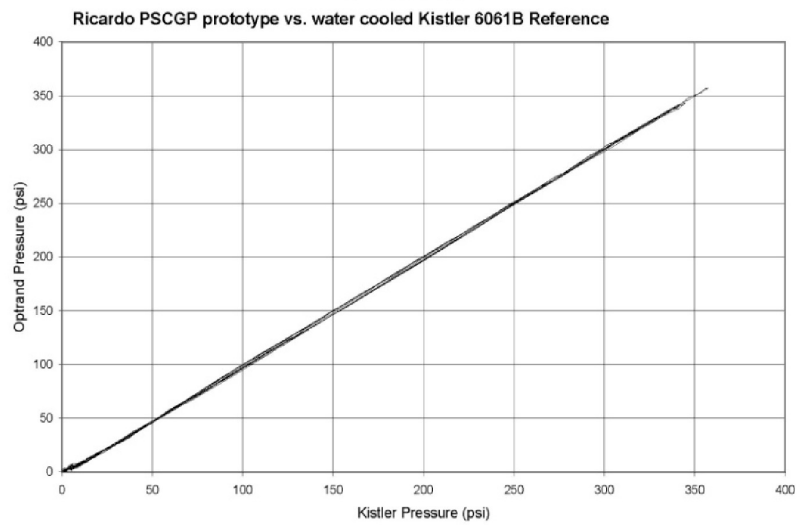

Fig. 11. Performance of glow plug mounted sensor

Signal to Noise ratio and no phase shift. The thermal shock error is less than 0.2 bar.

Figure 11 demonstrates the performance of another sensor based on the $1.7 \mathrm{~mm}$ diameter diaphragm welded this time into a glow plug heater. The data were collected on the same single cylinder gasoline engine as used to test the stand-alone sensor describe above. Accuracy within $\pm 1.5 \%$ of the reference transducer was recorded while the SNR was slightly lower than in the case of the stand alone

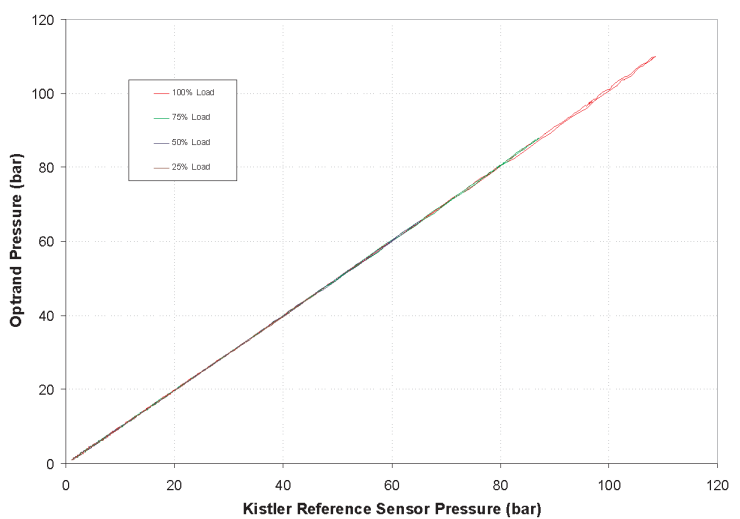

Fig. 12. Performance of gasket mounted sensor at different engine loads 
sensor associated with the sensor mounting in the glow plug heater $25 \mathrm{~mm}$ long. The thermal shock error was again below 0.2 bar owning to the low heat flux the diaphragm was exposed to due to $0.8 \mathrm{~mm}$ diameter of the pressure orifice and passage.

Figure 12 shows performance comparison obtained in a heavy duty 6-cylinder 6.71 diesel engine between a watercooled Kistler 6071 reference transducer and a $1.8 \mathrm{~mm}$ diameter fiber optic sensor installed into a cylinder head gasket [11].

Combustion profiles and Lissajous diagrams at a 2000 rpm engine speed are plotted under multiple load conditions of $25 \%, 50 \%, 75 \%$ and $100 \%$. The same slope of the sensor response is retained as the engine load and sensor temperature change, demonstrating the sensor's accuracy is independent to sensor temperature changes.

\section{Summary and conclusion}

The design and performance of a $1.7 \mathrm{~mm}$ diameter fiberoptic based cylinder pressure sensor was described packaged either as a stand-alone device or integrated with a glow plug or a cylinder head gasket. The sensor operates on the principle of light intensity changes transmitted by two optical fibers upon reflection from a metal diaphragm deflecting under the effect of pressure. The miniature opto-electronic and fiber optic components include an encoder-type, surface emitting, LED, small area Si PIN photodiode, and two 125 micron diameter multimode optical fibers. The fibers are hermetically bonded inside a metal ferrule using the metal glass-sealing principle. The ferrule is in turn hermetically welded into stainless steel housing with a hermetically welded Inconel 718 diaphragm. The latest generation of sensor signal conditioner fits on a $12.7 \mathrm{~mm}$ x $20 \mathrm{~mm}$ circuit board allowing its packaging into miniature device enclosures or "smart" automotive connectors. In comparison to a water cooled piezoelectric quartz transducer the present sensor offers the accuracy of $\pm 1.5 \%$ of reading at pressures above 5 bars and less than \pm 0.2 bar error at pressures below 5 bars. Such accuracy allows engine controls based on highly accurate values of the Indicated Mean Effective Pressure, Mass Fraction Burned, Maximum Pressure Gradient, and Peak Pressure. Benefitting from sensor's high accuracy at both low and high pressures the device uniquely enables pilot fuel injection closed-loop control as well as in-cylinder prediction of Mass Air Flow and engine $\mathrm{NO}_{x}$ emission levels in each cylinder.

\section{Bibliography}

[1] Sellnau M., Matekunas F.A., Battiston P.A.: Chang C.-F., Lancaster D.R., Cylinder-pressure-based engine control using pressure-ratio-management and low-cost non-intrusive cylinder pressure sensors, SAE Paper No. 2000-01-0932, 2000.

[2] Dorenkamp R., Gruber M.: US light duty clean diesel, Volkswagen/Audi Meeting Technical Challenge, DEER 2008.

[3] Huelser H., Neunteufl K., Unger E., Breitegger B.: Cylinderpressure-based engine control for diesel engines, 5th IAV Symposium, Berlin 2005.

[4] Schiefer D., Maennel R., Nordoni W.: Advantages of diesel engine control using in-cylinder pressure information for closed loop control, SAE Paper No. 03P-162.

[5] Nier T., Kulzer A., Karrelmeyer R.: Analysis of the combustion mode switch between SI and gasoline HCCI, SAE Paper No. 2012-01-1105, 2012

[6] Peng Z., Liu B., Tian L., Lu L.: Analysis of homogeneity factor for diesel PCCI combustion control, SAE Paper No. 2011-01-1832, 2011

[7] Splitter D., Reitz R., Hanson R.: High efficiency, low emissions RCCI combustion by use of a fuel additive, SAE Int. J. Fuels Lubr. 3(2):742-756, 2010.

Marek T. Włodarczyk, PhD - President and Chief Executive Officer of Optrand Incorporated in Plymouth, Michigan, USA..

Dr Marek T. Wtodarczyk - Prezes i Generalny Dyrektor firmy Optrand Incorporated w Plymouth, Michigan, USA.

e-mail:president@optrand.com
[8] Shimasaki Y., Kobayashi M., Sakamoto H., Eueno M., Hasegawa M., Yamaguchi S., Suzuki T.: Study of engine management system using in-cylinder pressure sensor integrated with spark plug, SAE Paper No. 2004-01-0519, 2004.

[9] He G., Wlodarczyk M.: Evaluation of a spark-plug-integrated fiber-optic combustion pressure sensor, SAE Paper No. 940381, 1994.

[10] Integrated pressure sensor systems in the cylinder-head gasket. MTZ - Motortechnische Zeitschrift 1/ 2004.

[11] Toth D., Shaw T., Wlodarczyk M., Cummings C.: Cylinder head gasket with integrated combustion pressure sensors for advanced engine controls, SAE Int. J. Engines 4(1):1235-1246, 2011.

[12] Houben H., Last B., Pechhold F., Pottiez C.: Glow plug with integrated combustion pressure sensor: a key component for controlled diesel combustion, Graz Symposium "The Operating Process of the Combustion Engine", 2007.

[13] Last B., Ramond A., Goretti S., Burrows J.: Glow plug integrated piezo ceramic combustion sensor for diesel engines with improved sensing element, SAE Paper No. 05P-155.

[14] Ulrich O., Wlodarczyk R., Wlodarczyk M.T.: High-accuracy low-cost cylinder pressure sensor for advanced engine controls, SAE Paper No. 2001-01-0991, 2001.

[15] Wlodarczyk M.T.: Embedded fiber-optic combustion pressure sensor for automotive engine controls, FISITA World Automotive Congress, Paris 1998.

[16] Wlodarczyk M.: High accuracy glow plug integrated cylinder pressure sensor for closed loop engine control, SAE Paper No. 2006-01-0184, 2006. 